Check for updates

Cite this: Mater. Adv., 2020, 1,3358

Received 2nd July 2020,

Accepted 13th October 2020

DOI: 10.1039/d0ma00476f

rsc.li/materials-advances

\title{
Cyclic siloxanes conjugated with fluorescent aromatic compounds as fluoride sensors $\dagger$
}

\author{
Nicha Prigyai, ${ }^{a}$ Supphachok Chanmungkalakul, ${ }^{a}$ Sutthiroj Thanyalax, ${ }^{a}$ \\ Mongkol Sukwattanasinitt ${ }^{\mathrm{bc}}$ and Vuthichai Ervithayasuporn (D) *a
}

\begin{abstract}
Cyclic siloxanes conjugated with anthracene $\left(\mathbf{D}_{\mathbf{4}} \mathbf{A n}\right)$ and pyrene $\left(\mathbf{D}_{\mathbf{4}} \mathbf{P y}\right)$ were prepared via Heck coupling reactions of 2,4,6,8-tetramethyl-2,4,6,8-tetravinylcyclotetrasiloxane with 9-bromoanthracene and 1-bromopyrene, respectively. These materials exhibited solvent-dependent fluorescence with the largest Stokes shift of up to $\sim 146 \mathrm{~nm}$, confirming the presence of intramolecular exciplex formation among the fluorophores within a cyclic siloxane. After reacting with fluoride ions, blue-shifted emissions of $\mathbf{D}_{\mathbf{4}} \mathbf{A n}$ and $\mathbf{D}_{\mathbf{4}} \mathbf{P y}$ in organic solvents were observed; it suggests an increase in monomer emission as a result of exciplex preclusion via $\mathrm{Si}-\mathrm{F}$ bond formation. Moreover, the colorless solutions of $\mathbf{D}_{\mathbf{4}} \mathrm{An}$ and $\mathbf{D}_{\mathbf{4}} \mathbf{P y}$ in THF turned pink and orange, respectively, in the presence of excessive $\mathrm{F}^{-}$, which also suggested the formation of charge-transfer complexes. The interactions between cyclic siloxanes and fluoride ions were also studied via FTIR, ESI-MS and NMR experiments. Computational modeling studies revealed that fluoride played an important role in distorting the geometry of cyclic siloxanes by interrupting excimers of fluorescent aromatic rings in the side-chain.
\end{abstract}

\section{Introduction}

Polysiloxane $\left(\mathrm{R}_{2} \mathrm{SiO}\right)_{n}$ can be found as major components in commercial products in our daily life such as scented hydrogels, silicon ware, household products, personal care products, electrical devices and cookware. ${ }^{1,2}$ They are described as organosilicon compounds that include silicon-oxygen backbones with organic side chains attached to each silicon atom. ${ }^{3-5}$ Flexible siloxane polymers or silicones have been extensively used due to its high thermal stability, chemical resistance, low tension, smooth texture, and non-toxicity and biocompatibility of compounds depending on functionalization. ${ }^{6-9}$ Siloxanes have two general forms: cyclic and linear. ${ }^{10}$ For cyclic siloxanes, silicon and oxygen atoms bond and connect at each end to form a ring structure. ${ }^{411}$ Cyclic siloxanes are used in a wide range of applications due to the hydrocarbon side chain of siloxane, which is beneficial for side-chain functionalization. In terms of synthesis, cyclic siloxanes are frequently used as

\footnotetext{
${ }^{a}$ Department of Chemistry, Center of Excellence for Innovation in Chemistry (PERCH-CIC), and Center for Inorganic and Materials Chemistry, Faculty of Science, Mahidol University, Rama VI road, Ratchathewi, Bangkok 1040o, Thailand. E-mail: vuthichai.erv@mahidol.edu

${ }^{b}$ Department of Chemistry, Faculty of Science, Chulalongkorn University, Bangkok, 10330, Thailand

${ }^{c}$ Nanotec-CU Center of Excellence on Food and Agriculture, Department of Chemistry, Faculty of Science, Chulalongkorn University, Bangkok, 10330, Thailand

$\dagger$ Electronic supplementary information (ESI) available. See DOI: 10.1039/ doma00476f
}

precursors for the synthesis of high performance polysiloxane elastomers, ${ }^{12,13}$ and as cross-linking agents to strengthen materials. ${ }^{14-16}$ Recently, polysiloxanes and cyclic siloxanes functionalized with fluorophores have exhibited excellent sensing ability to detect specific chemical species. For example, Ren et al. reported tetraphenylethene units modified into polysiloxane chains possessing fluorescence ability and capable of detecting the vapor-phase of explosive compounds. ${ }^{17}$ Lang et al. successfully synthesized a siloxane polymer containing fluoranthene groups that showed high thermal stability and strong fluorescence emission that can be quenched by picric acid detection. ${ }^{18}$ Polydimethylsiloxane bearing spirobenzopyran, which acted as a colorimetric probe for $\mathrm{pH}$ determination and $\mathrm{Ag}^{+}$and $\mathrm{Fe}^{3+}$ ion detection, was reported by $\mathrm{Li}$ and co-workers. ${ }^{19}$ Recently, Lin et al. studied pyrenyl-functionalized cyclic siloxane and polysiloxane for nitroaromatic compound detection. ${ }^{20}$ Along this line, the development of anion sensors from cyclic siloxanes would be very intriguing and challenging. In the meantime, a lot of molecular interactions were proposed for designing probes, including hydrogen bonding, ${ }^{21,22}$ electrostatic interaction, ${ }^{23}$ deprotonation, ${ }^{24,25}$ nucleophilic substitution ${ }^{26}$ and $\mathrm{Si}-\mathrm{O}$ bond cleavage. ${ }^{27,28}$

In the last two decades, the usage of organosilica-based cage materials has expanded to cover many fields of applications such as catalytic supports, polymers, biocompatible materials and sensors. $^{29}$ Previously, we have reported fluorescent organosilica-based cage materials for both efficient fluoride detection and adsorption. ${ }^{30-32}$ The principle of electrostatic interaction between fluoride ions and the potential surface of 
organosilica cages, which plays a role in the attraction of positive and negative parts to each other, in those materials has been proposed. ${ }^{33}$ Those responsive changes in fluorescence emission involve the conversion of an exciplex signal to a monomer signal due to $\mathrm{F}^{-}$ induced conformational changes of the cage. ${ }^{34}$ Intriguingly, the less rigid cyclic siloxanes, in comparison with the cage siloxanes, are worth exploring as they are more common starting materials for silicone and gel materials. Herein, two cyclic siloxanes conjugated with anthracene $\left(\mathbf{D}_{\mathbf{4}} \mathbf{A n}\right)$ and pyrene $\left(\mathbf{D}_{\mathbf{4}} \mathbf{P y}\right)$ were successfully synthesized with high fluorescence emission. UV-vis absorption and fluorescence spectroscopy were used to investigate their absorption and emission. Furthermore, the interactions of fluoride and cyclic siloxanes were supported by computations as well as FTIR and ${ }^{19}$ F NMR spectroscopy. Quantum calculations were performed to propose the optimized geometry as well as changes in the conformation of the fluorophores. This work aims to demonstrate the application of cyclic siloxanes as an anchoring platform for anion sensors.

\section{Results and discussion}

\section{Synthesis and solvent effects of cyclic siloxanes ( $\mathrm{D}_{4} \mathrm{An}$ and $\left.\mathrm{D}_{\mathbf{4}} \mathrm{Py}\right)$}

Compounds of $\mathbf{D}_{\mathbf{4}} \mathbf{A n}$ and $\mathbf{D}_{\mathbf{4}} \mathbf{P y}$ were synthesized via Heck coupling reaction from 2,4,6,8-tetramethyl-2,4,6,8-tetravinylcyclotetrasiloxane and 9-bromoanthracene or 1-bromopyrene as precursors (Scheme 1). A dark-orange powder of $\mathbf{D}_{\mathbf{4}} \mathbf{A n}$ and yellow powder of $\mathbf{D}_{\mathbf{4}} \mathbf{P y}$ were obtained in $72 \%$ and $87 \%$ yields, respectively (Fig. S1, ESI $\dagger$ ). The solid state ${ }^{1} \mathrm{H}$ MAS NMR spectrum of $\mathbf{D}_{\mathbf{4}}$ An shows a broad peak at $6.28 \mathrm{ppm}$ and sharp peaks in the range of 0.02-1.29 ppm, which indicate the presence of aromatic and methyl groups, respectively. For $\mathrm{D}_{4} \mathrm{Py}$, a broad peak of pyrene appeared at $5.97 \mathrm{ppm}$ while a sharp peak of the methyl group was found at 0.03 ppm (Fig. S2, ESI $\dagger$ ). The solid state ${ }^{29}$ Si MAS NMR spectra of $\mathbf{D}_{\mathbf{4}} \mathbf{A n}$ and $\mathbf{D}_{\mathbf{4}} \mathbf{P y}$ only showed a singlet peak at -32 and -30 ppm, respectively (Fig. 5), confirming the formation of the siloxane (D type) network. These solid products could be a mixture of 2 and 4 fluorophore units on cyclic siloxanes, as shown in the MALDI-TOF MS spectra, confirming the coupling of the cyclic products with 4 anthracene units with the found $m / z$ at 1049.429 (calcd $\left[\mathrm{C}_{68} \mathrm{H}_{56} \mathrm{O}_{4} \mathrm{Si}_{4}+\mathrm{H}^{+}\right]: m / z$ 1049.333) as well as 4 pyrene units with the found $\mathrm{m} / \mathrm{z}$ at 1145.778 (calcd $\left[\mathrm{C}_{76} \mathrm{H}_{56} \mathrm{O}_{4} \mathrm{Si}_{4}+\mathrm{H}^{+}\right]: m / z$ 1145.333) (Fig. S3, ESI $\dagger$ ).

It is well-known that anthracene and pyrene monomers possess solvent-dependent properties where solvent polarity could induce different ratios of monomer and excimer emissions. ${ }^{35-38}$ The fluorescence intensity of both 9-bromoanthracene and 1-bromopyrene slightly increased with the increase of solvent polarity while their fluorescence intensity showed two or three sharp peaks (Fig. 1a and b), confirming the presence of monomer emission. However, small broad peaks at longer wavelengths were observed, attributed to intermolecular excimer formation. ${ }^{39,40}$ Confirming the successful synthesis of cyclic siloxanes conjugated with fluorescent aromatic compounds, the spectra of both cyclic siloxanes in organic solvents appeared broader and showed a red-shift of fluorescence emissions at longer wavelengths (450-600 nm) (Fig. 1c and d). This result indicated significant intramolecular exciplex formation among the fluorophore units within the cyclic siloxanes; ${ }^{41}$ at the same time, the largest Stokes shift $(\Delta \lambda=146 \mathrm{~nm})$ from the absorption band at $350 \mathrm{~nm}$ to the excimer emission band at $496 \mathrm{~nm}$ of $\mathbf{D}_{\mathbf{4}} \mathbf{P y}$ was observed in DMSO as a representative of highly polar solvents (Fig. 1d). In slightly polar solvents, the exciplex emissions of $\mathbf{D}_{\mathbf{4}}$ Py showed a shorter Stokes shift $(126 \mathrm{~nm}$ for toluene and THF). Therefore, intramolecular exciplex formation within cyclic siloxanes of both $\mathbf{D}_{\mathbf{4}} \mathbf{A n}$ and $\mathbf{D}_{\mathbf{4}} \mathbf{P y}$ is favourable in polar organic solvents. In comparison with $\mathbf{D}_{\mathbf{4}} \mathbf{P y}$, all $\mathbf{D}_{\mathbf{4}} \mathbf{A n}$ solutions gave bright blue emission and a shorter Stokes shift of $68-73 \mathrm{~nm}$, measured using the differences between an absorption peak at 376-379 $\mathrm{nm}$ and a peak of excimer emission at 446-452 nm (Fig. 1c). It was suggested that $\pi-\pi$ interactions in anthracene units within cyclic siloxanes are weaker than those within pyrenyl siloxanes. This suggestion can also be confirmed by the solid-state fluorescence spectra of $\mathbf{D}_{\mathbf{4}} \mathbf{A n}$ and $\mathbf{D}_{\mathbf{4}} \mathbf{P y}$ that showed broad spectra with only single peaks at 477 and $532 \mathrm{~nm}$, respectively (Fig. 1e and f).

\section{Selectivity test}

The fluorescence emission patterns of $\mathbf{D}_{\mathbf{4}} \mathbf{A n}$ and $\mathbf{D}_{\mathbf{4}} \mathbf{P y}$ before and after the addition of anions were investigated in four solvents (e.g. toluene, THF, DMF and DMSO). When 1 equiv. of tetrabutylammonium salts (TBA-X: $\mathrm{X}=\mathrm{F}^{-}, \mathrm{Cl}^{-}, \mathrm{Br}^{-}, \mathrm{CN}^{-}$, $\mathrm{ClO}_{4}{ }^{-}, \mathrm{NO}_{3}{ }^{-}$and $\mathrm{PO}_{4}{ }^{3-}$ ) was added into both $\mathbf{D}_{4} \mathbf{A n}$ and $\mathbf{D}_{4} \mathbf{P y}$ solutions except in DMSO where 10 equiv. was added, only $\mathrm{F}^{-}$ can significantly enhance the fluorescence intensity of the monomer emission (Fig. 2) with a deep blue color in all solvents (Fig. 3a). For example, upon addition of $\mathrm{F}^{-}$into $\mathbf{D}_{\mathbf{4}} \mathbf{P y}$ solutions, the monomer emissions $\left(\lambda_{\max } \sim 395 \mathrm{~nm}\right)$ increased while the
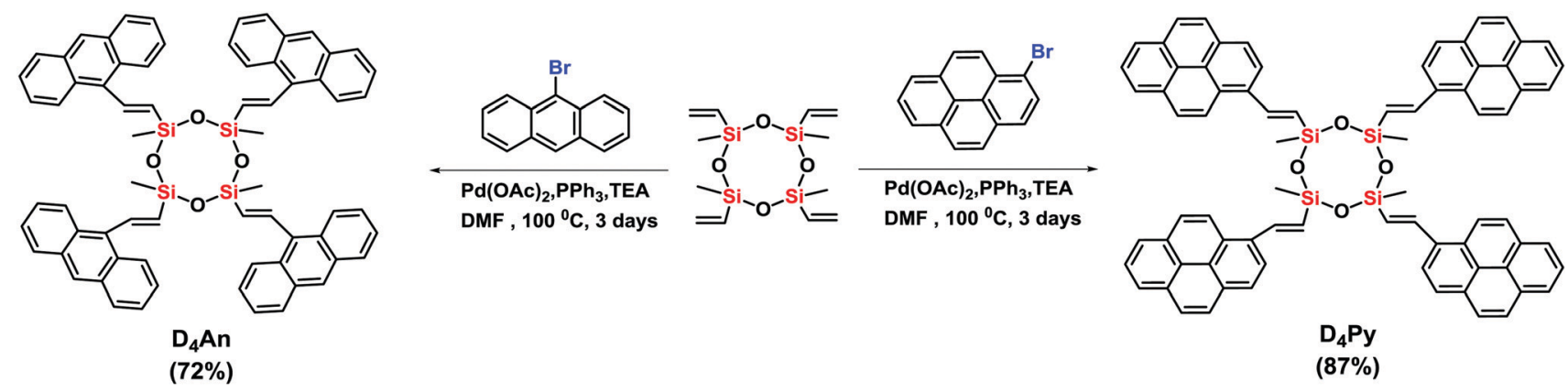

Scheme 1 Synthesis of cyclic siloxanes conjugated with anthracene $\left(\mathbf{D}_{\mathbf{4}} \mathbf{A n}\right)$ and pyrene $\left(\mathbf{D}_{\mathbf{4}} \mathbf{P y}\right)$. 
a)

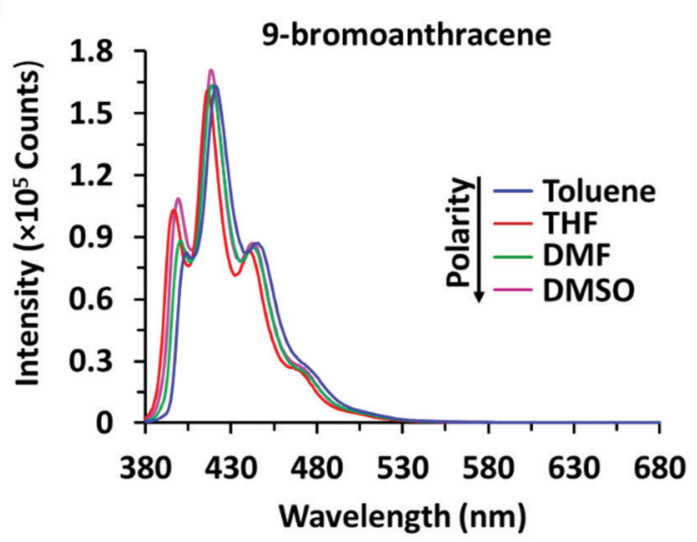

c)

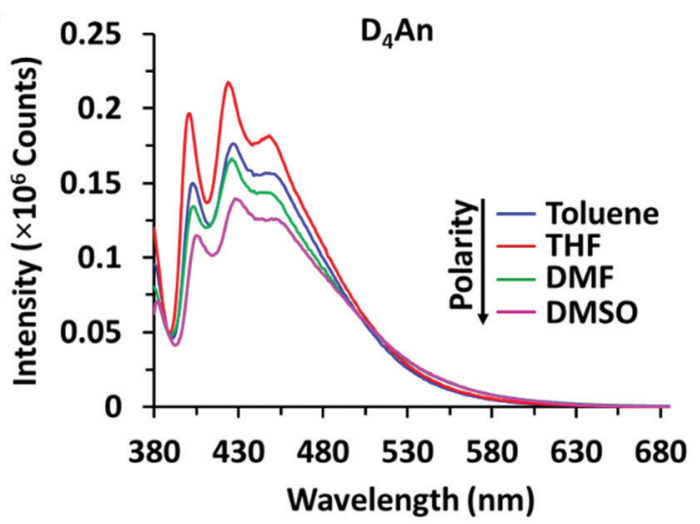

e)

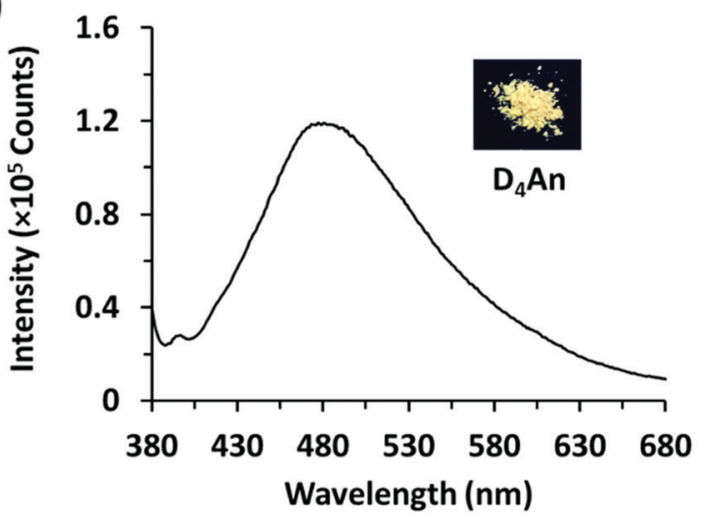

b)

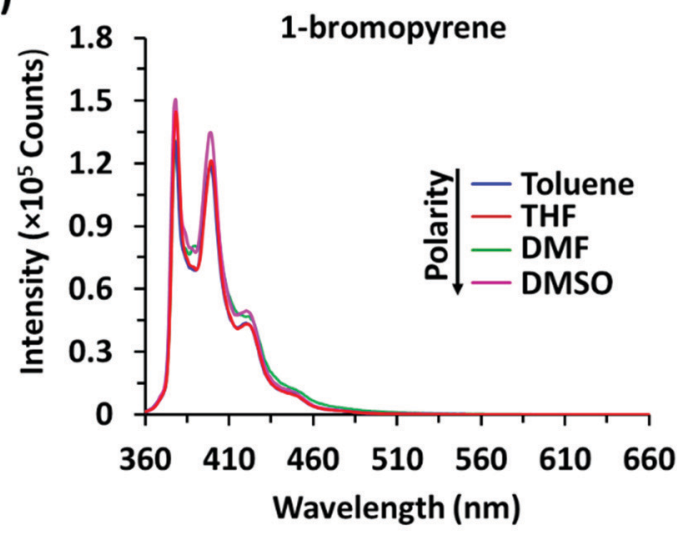

d)

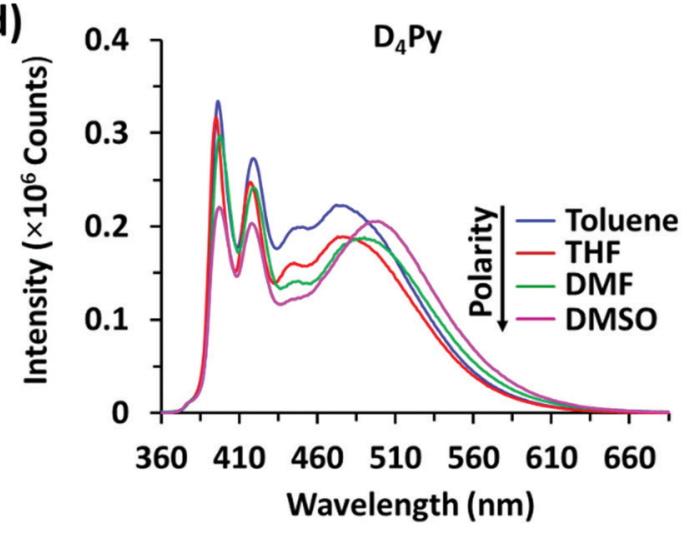

f)

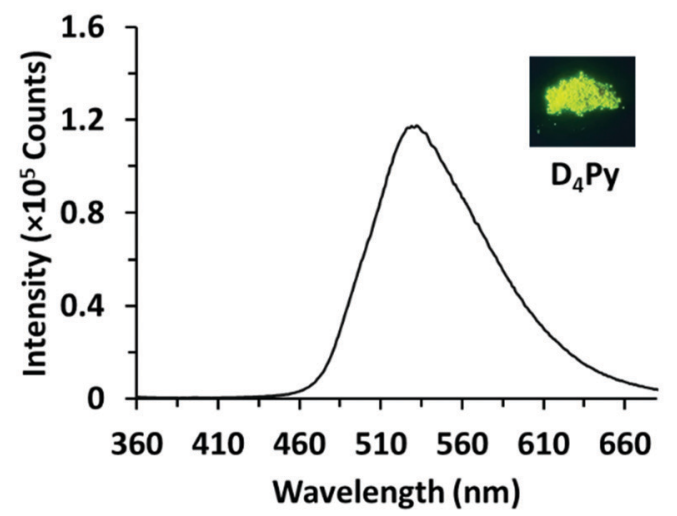

Fig. 1 Fluorescence spectra of (a) 9-bromoanthracene $\left(1 \times 10^{-4} \mathrm{M}\right)$ at $\lambda_{\mathrm{ex}}=370 \mathrm{~nm}$, (b) 1 -bromopyrene $\left(1 \times 10^{-4} \mathrm{M}\right)$ at $\lambda_{\mathrm{ex}}=346 \mathrm{~nm},(\mathrm{c}) \mathbf{D}_{4} \mathrm{An}\left(2 \times 10^{-5}\right.$ M) at $\lambda_{\mathrm{ex}}=378 \mathrm{~nm}$, and (d) $\mathbf{D}_{\mathbf{4}} \mathbf{P y}\left(1 \times 10^{-5} \mathrm{M}\right)$ at $\lambda_{\mathrm{ex}}=350 \mathrm{~nm}$; solid-state fluorescence spectra of (e) $\mathbf{D}_{4} \mathrm{An}$ at $\lambda_{\mathrm{ex}}=378 \mathrm{~nm}$ and (f) $\mathbf{D}_{\mathbf{4}} \mathbf{P y}$ at $\lambda_{\mathrm{ex}}=350 \mathrm{~nm}$.

intramolecular exciplex emissions $\left(\lambda_{\max } \sim 480 \mathrm{~nm}\right)$ decreased (Fig. 2). This result confirmed that $\mathrm{F}^{-}$was involved in the reorganization and orientation of the pyrene units. The green emission of the $\mathbf{D}_{\mathbf{4}} \mathbf{P y}$ solution changed to deep blue emission after adding fluoride, as shown in Fig. 3a, which also supported the separation of the intramolecular pyrene-pyrene excimer into a single monomer. Moreover, after the addition of excess anions (200 equiv.) into both cyclic siloxanes in all solvents, these compounds additionally responded to $\mathrm{CN}^{-}$and $\mathrm{PO}_{4}{ }^{3-}$ (Fig. S4 and S5, ESI $\dagger$ ). The fluorescence emissions of $\mathbf{D}_{\mathbf{4}} \mathbf{A n}$ and $\mathbf{D}_{\mathbf{4}} \mathbf{P y}$ could also be intensified in highly polar solvents (DMF and DMSO) after the addition of $\mathrm{F}^{-}, \mathrm{CN}^{-}$and $\mathrm{PO}_{4}{ }^{3-}$. Nonetheless, the fluorescence emissions of $\mathbf{D}_{\mathbf{4}} \mathbf{P y}$ in THF with a large excess of $\mathrm{F}^{-}$were completely quenched (Fig. S5, ESI $\dagger$ ). Furthermore, only $\mathrm{F}^{-}$(200 equiv.) could induce naked-eye color changes of $\mathbf{D}_{\mathbf{4}} \mathbf{A n}$ and $\mathbf{D}_{\mathbf{4}} \mathbf{P y}$ solutions in THF from colorless to pink and orange, respectively (Fig. 3b). These results suggested charge-transfer (CT) complexation between $\mathrm{F}^{-}$and the fluorophores via anion- $\pi$ interaction. ${ }^{31}$ Notably, single fluorophore compounds such as 1-bromopyrene and 9bromoanthracene did not show any color change suggesting that the anchoring of multiple fluorophores within the same molecule was necessary to promote this interaction. 

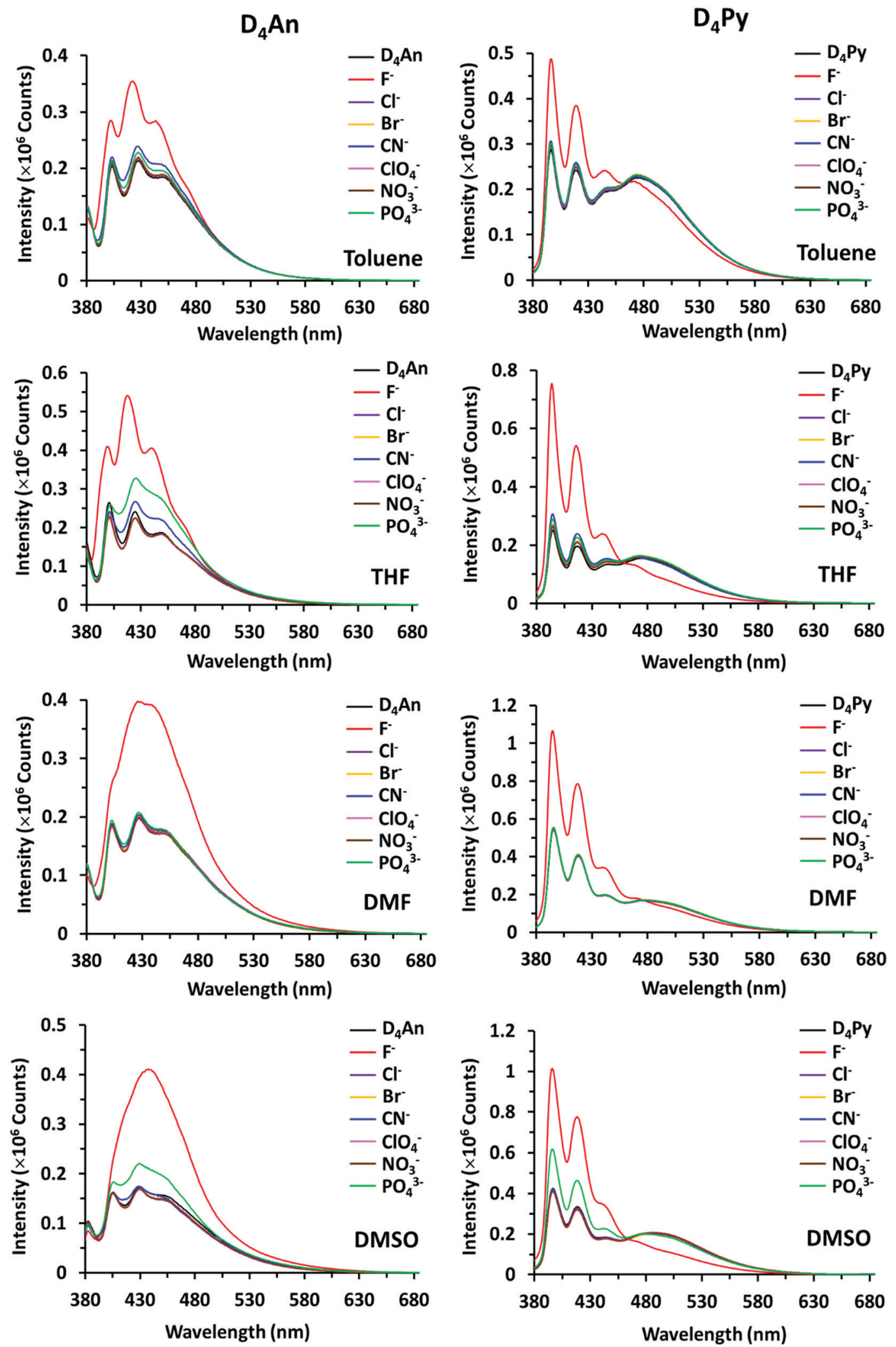

Fig. 2 Fluorescence spectra of $\mathbf{D}_{\mathbf{4}} \mathbf{A n}\left(2 \times 10^{-5} \mathrm{M}\right)$ at $\lambda_{\mathrm{ex}}=378 \mathrm{~nm}$ (left) and $\mathbf{D}_{\mathbf{4}} \mathbf{P y}\left(1 \times 10^{-5} \mathrm{M}\right)$ at $\lambda_{\mathrm{ex}}=350 \mathrm{~nm}$ (right) in various solvents before and after the addition of 1 equiv. of anions. 

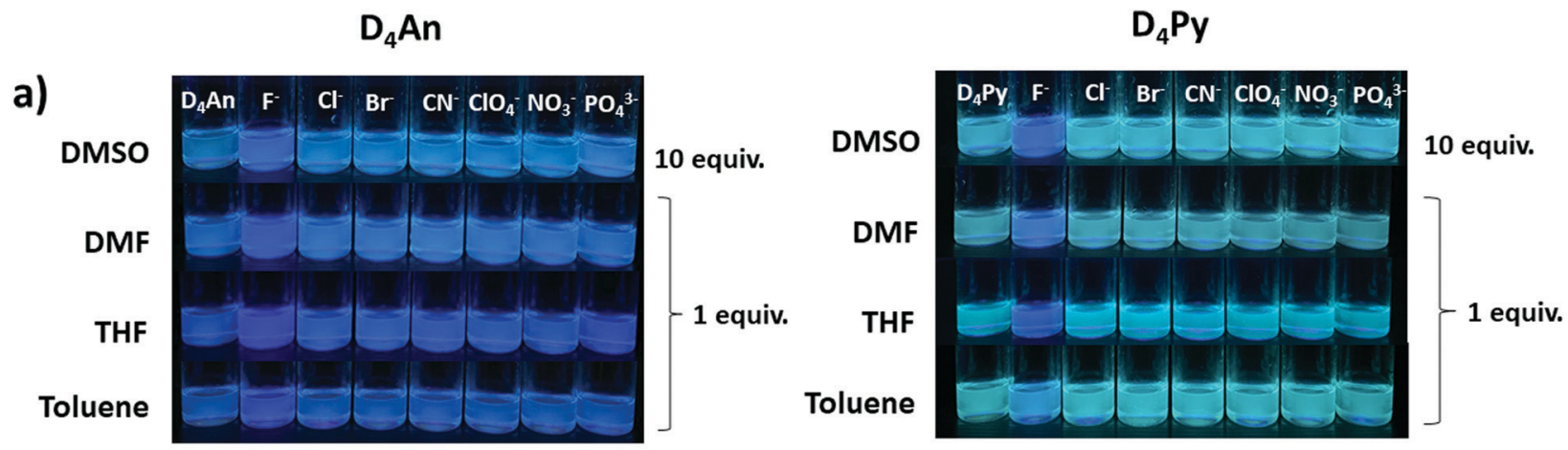

b)

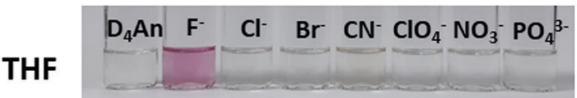

THF

$\mathrm{D}_{4} \mathrm{Py} \quad \mathrm{F}^{-} \quad \mathrm{Cl}^{-} \mathrm{Br} \mathrm{CN}^{-} \mathrm{ClO}_{4}^{-} \mathrm{NO}_{3}^{-} \mathrm{PO}_{4}^{3-}$

Fig. 3 Selective images of (a) $\mathbf{D}_{4} \mathbf{A n}\left(2 \times 10^{-5} \mathrm{M}\right)$ (left) and $\mathbf{D}_{\mathbf{4}} \mathbf{P y}\left(1 \times 10^{-5} \mathrm{M}\right)$ (right) after the addition of anions $(1$ and 10 equiv.) in various solvents under a UV lamp; (b) $\mathbf{D}_{4}$ An $\left(4 \times 10^{-5} \mathrm{M}\right)$ (left) and $\mathbf{D}_{4} \mathbf{P y}\left(2 \times 10^{-5} \mathrm{M}\right)$ (right) in THF upon the addition of anions (200 equiv.) under daylight.

\section{Kinetic study}

The fluorescence responses of $\mathbf{D}_{\mathbf{4}} \mathbf{A n}$ and $\mathbf{D}_{\mathbf{4}} \mathbf{P y}$ after adding 200 equiv. of $\mathrm{F}^{-}, \mathrm{CN}^{-}$, and $\mathrm{PO}_{4}{ }^{3-}$ were measured at a fixed excitation wavelength for 30 minutes. For $\mathrm{F}^{-}$, the change in fluorescence signal occurred and completed almost instantly in DMF. In contrast, the response was slower in slightly polar solvents like toluene, as shown in Fig. S6 (ESI $\dagger$ ). For $\mathrm{CN}^{-}, \mathbf{D}_{\mathbf{4}} \mathbf{A n}$ responses were slower in all solvents, but a faster response was seen in slightly polar solvents for $\mathbf{D}_{4} \mathbf{P y}$. In addition, $\mathrm{PO}_{4}{ }^{3-}$ caused a fast kinetic response of $\mathbf{D}_{\mathbf{4}} \mathbf{P y}$ in highly polar solvents (DMSO and DMF), but a similar rate in all solvents for $\mathbf{D}_{\mathbf{4}} \mathbf{A n}$. The pseudo-first order kinetic rate constants of the three ions were calculated and displayed in Table S1 (ESI $\dagger$ ).

\section{Quantitative analyses of fluoride}

An optimized concentration of $\mathbf{D}_{\mathbf{4}} \mathbf{A n}$ at $2 \times 10^{-5} \mathrm{M}$ was used in fluorescence titration for quantitative analysis of $\mathrm{F}^{-}$. The fluorescence emission of $\mathbf{D}_{\mathbf{4}} \mathbf{A n}$ in THF displayed a peak maximum at $427 \mathrm{~nm}$; after the addition of $\mathrm{F}^{-}$into the $\mathbf{D}_{\mathbf{4}} \mathbf{A n}$ solution, the peak shifted to $420 \mathrm{~nm}$, and it then increased when the concentration of $\mathrm{F}^{-}$was increased (Fig. 4a). The same trend of emission spectra was observed in toluene, DMF and DMSO, as shown in Fig. S7 (ESI $\dagger)$. The association constant $\left(K_{\mathrm{a}}\right)$ was calculated based on Benesi-Hildebrand plots from titration spectra. The $K_{\mathrm{a}}$ values were $4.9,11.8,2.5$ and $3.1\left(\times 10^{4} \mathrm{M}^{-1}\right)$ in toluene, THF, DMF and DMSO, respectively. The detection limits of $\mathrm{F}^{-}$in $\mathbf{D}_{\mathbf{4}} \mathbf{A n}$ in toluene, THF, DMF and DMSO were found to be $0.2,0.3,0.8$ and $1.7 \mu \mathrm{M}$, respectively. However, the optimized concentration of $\mathbf{D}_{\mathbf{4}} \mathbf{P y}$ of $1 \times 10^{-5} \mathrm{M}$ was used for performing fluoride titration. The monomeric emission spectra in the range of 395-397 $\mathrm{nm}$ increased, but the peak intensities in the range of 475-482 $\mathrm{nm}$, which represented intermolecular exciplex formation dropped and generated isosbestic points at 470, 462, 474 and $476 \mathrm{~nm}$ in toluene, THF, DMF and DMSO, respectively (Fig. 4a and Fig. S7, ESI $\dagger$ ). The association constant values of $\mathbf{D}_{\mathbf{4}} \mathbf{P y}$ were calculated as $6.3,3.4,4.5$ and $3.3\left(\times 10^{5} \mathbf{M}^{-1}\right)$, which were higher than those of $\mathbf{D}_{\mathbf{4}} \mathbf{A n}$, indicating that $\mathbf{D}_{\mathbf{4}} \mathbf{P y}$ could bind more strongly with fluoride ions than $\mathbf{D}_{\mathbf{4}} \mathbf{A n}$. Notably, the detection limits of $\mathbf{D}_{\mathbf{4}} \mathbf{P y}$ in toluene, THF, DMF and DMSO were $0.3,0.4,1.0$ and $1.0 \mu \mathrm{M}$, respectively. These results indicate that $\mathbf{D}_{\mathbf{4}} \mathbf{A n}$ and $\mathbf{D}_{\mathbf{4}} \mathbf{P y}$ exhibit good selectivity and sensitivity for detecting fluoride ions. The association constant $\left(K_{\mathrm{a}}\right)$, LOD and LOQ of $\mathbf{D}_{\mathbf{4}} \mathbf{A n}$ and $\mathbf{D}_{\mathbf{4}} \mathbf{P y}$ with fluoride in various solvents are summarized in Table S2 (ESI $\dagger$ ).

\section{Proposed mechanism of fluoride interaction}

Since $\mathbf{D}_{\mathbf{4}} \mathbf{A n}$ and $\mathbf{D}_{\mathbf{4}} \mathbf{P y}$ are structures of cyclic siloxanes conjugated with a polyaromatic group, both compounds exhibited a positive contour within the cyclic siloxanes, which provides good possibilities for attracting $\mathrm{F}^{-} \cdot 33$ After the addition of $\mathrm{F}^{-}$in the system, the $\mathrm{Si}-\mathrm{F}$ bond can change the conformation of fluorophores on cyclic siloxanes, the destruction of excimers was observed from the fluorescence emission spectra (Fig. 4a and c) and then the cyclic siloxanes were cleaved. The FTIR results showed that $\mathbf{D}_{\mathbf{4}} \mathbf{A n}$ and $\mathbf{D}_{\mathbf{4}} \mathbf{P y}$ exhibited the asymmetric stretching vibration of $\mathrm{Si}-\mathrm{O}-\mathrm{Si}$ at $1025 \mathrm{~cm}^{-1}$. Nevertheless, a broad peak at around $3378 \mathrm{~cm}^{-1}(-\mathrm{OH})$ and a sharp peak at $882 \mathrm{~cm}^{-1}(\mathrm{Si}-\mathrm{OH})$ appeared after the addition of fluoride (1 equiv.) into both $\mathbf{D}_{\mathbf{4}} \mathbf{A n}$ and $\mathbf{D}_{\mathbf{4}} \mathbf{P y}$ (Fig. S8, ESI $\dagger$ ). These results confirmed that the cyclic siloxane was cleaved by fluoride ions. Moreover, the ${ }^{19} \mathrm{~F}$ NMR titration experiment in $\mathrm{CDCl}_{3}$ showed free TBAF at $-112 \mathrm{ppm}$. The signal appeared at $-124 \mathrm{ppm}$ represented the free $\mathrm{F}^{-}$on a glass tube $\left(\mathrm{SiF}_{6}{ }^{2-}\right) .{ }^{42,43}$ Upon the addition of fluoride into $\mathbf{D}_{\mathbf{4}} \mathbf{A n}$ and $\mathbf{D}_{\mathbf{4}} \mathbf{P y}$ solutions, new peaks appeared at $-129 \mathrm{ppm}$, indicating the interaction between the cyclic siloxane and $\mathrm{F}^{-}$(Fig. S9 and S10, ESI $\dagger$ ). Interestingly, their solid state ${ }^{29} \mathrm{Si}$ MAS NMR spectra after the addition of $\mathrm{F}^{-}$showed new smaller peaks at -55 and $-64 \mathrm{ppm}$ for $\mathbf{D}_{\mathbf{4}} \mathbf{A n}$, while the peak of $\mathbf{D}_{\mathbf{4}} \mathbf{P y}$ almost completely shifted from -30 to $-66 \mathrm{ppm}$. These NMR results suggested that the $\mathrm{Si}-\mathrm{O}$ linkages of cyclic siloxanes were not only cleaved using $\mathrm{F}^{-}$, but some $\mathrm{Si}-\mathrm{C}$ bonds were also broken and rearranged to form silsesquioxanes ( $\mathrm{T}$ unit) of silicon (Fig. 5). ${ }^{44,45}$ Furthermore, the ESI-MS results of $\mathbf{D}_{\mathbf{4}} \mathbf{A n}$ and $\mathbf{D}_{\mathbf{4}} \mathbf{P y}$ with fluoride also showed small fractions of cyclic siloxane caused by fluoride ions (Fig. S11 and S12, ESI $\dagger$ ). These results also validated the fact 
a)

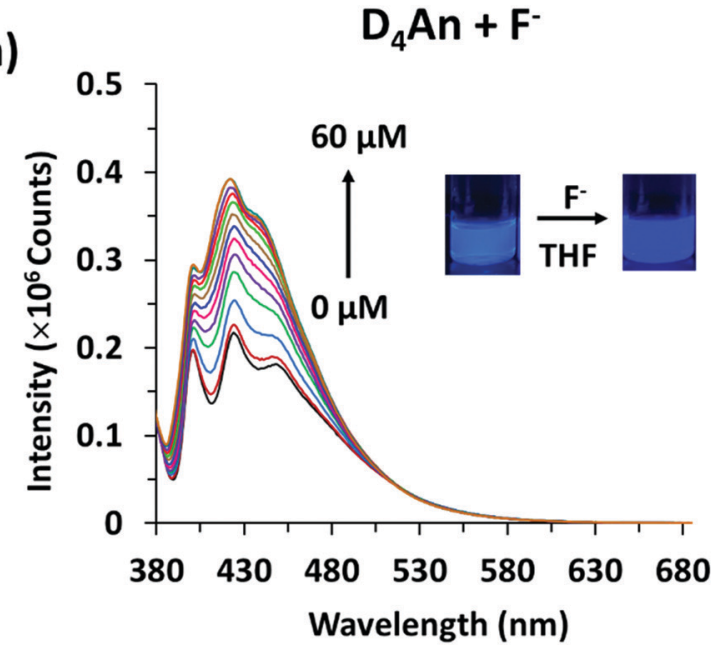

b)

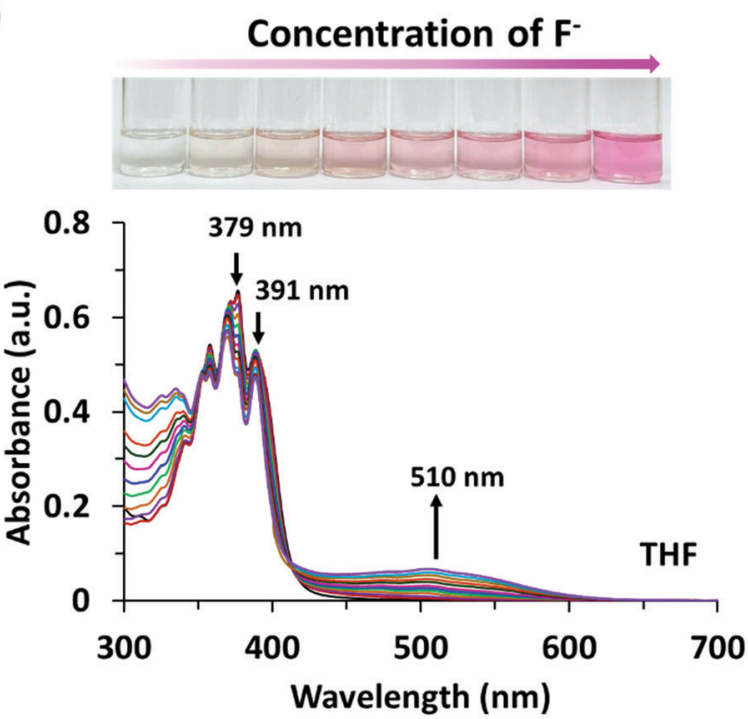

$\mathrm{D}_{4} \mathrm{Py}+\mathrm{F}^{-}$

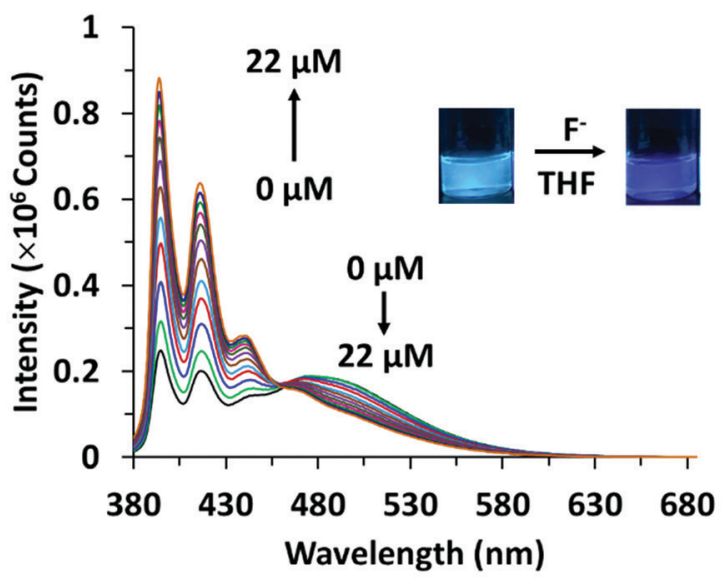

\section{Concentration of $\mathrm{F}^{-}$}

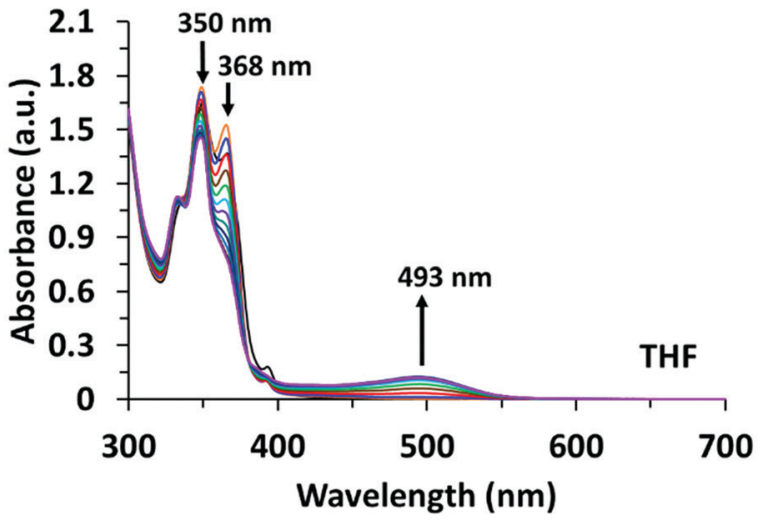

c)

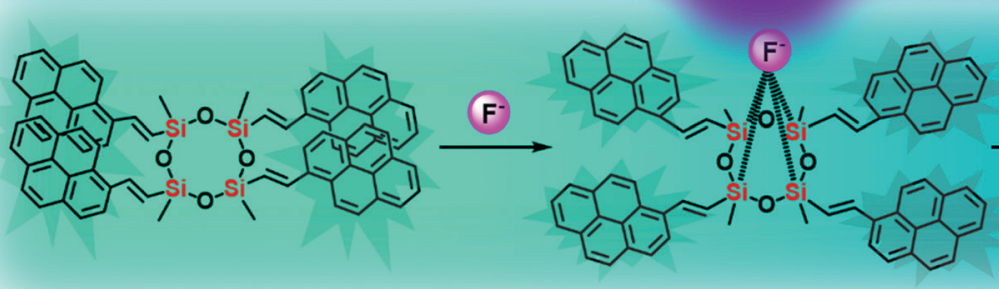

Excimer emission

(Longer wavelength)

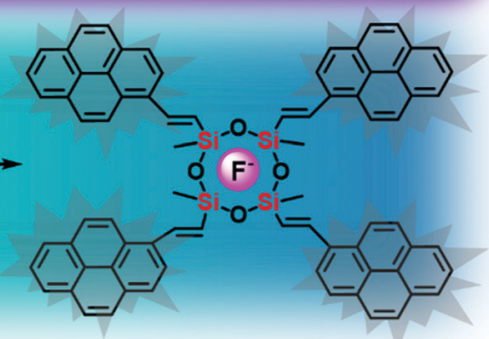

Molecular emission

(Shorter wavelength)

Fig. 4 (a) Fluorescence titration spectra of $\mathbf{D}_{4} \mathbf{A n}\left(2 \times 10^{-5} \mathrm{M}\right)$ at $\lambda_{\text {ex }}=378 \mathrm{~nm}$ (left) and $\mathbf{D}_{4} \mathbf{P y}\left(1 \times 10^{-5} \mathrm{M}\right)$ at $\lambda_{\text {ex }}=350 \mathrm{~nm}$ (right) in THF at different concentrations of fluoride; (b) UV-vis adsorption spectra of $\mathbf{D}_{4} \mathbf{A n}\left(4 \times 10^{-5} \mathrm{M}\right)$ (left) and $\mathbf{D}_{\mathbf{4}} \mathbf{P y}\left(2 \times 10^{-5} \mathrm{M}\right)$ (right) in THF at different concentrations of fluoride; and (c) proposed interactions between $\mathbf{D}_{4} \mathbf{P y}$ and fluoride according to their fluorescence characters. 

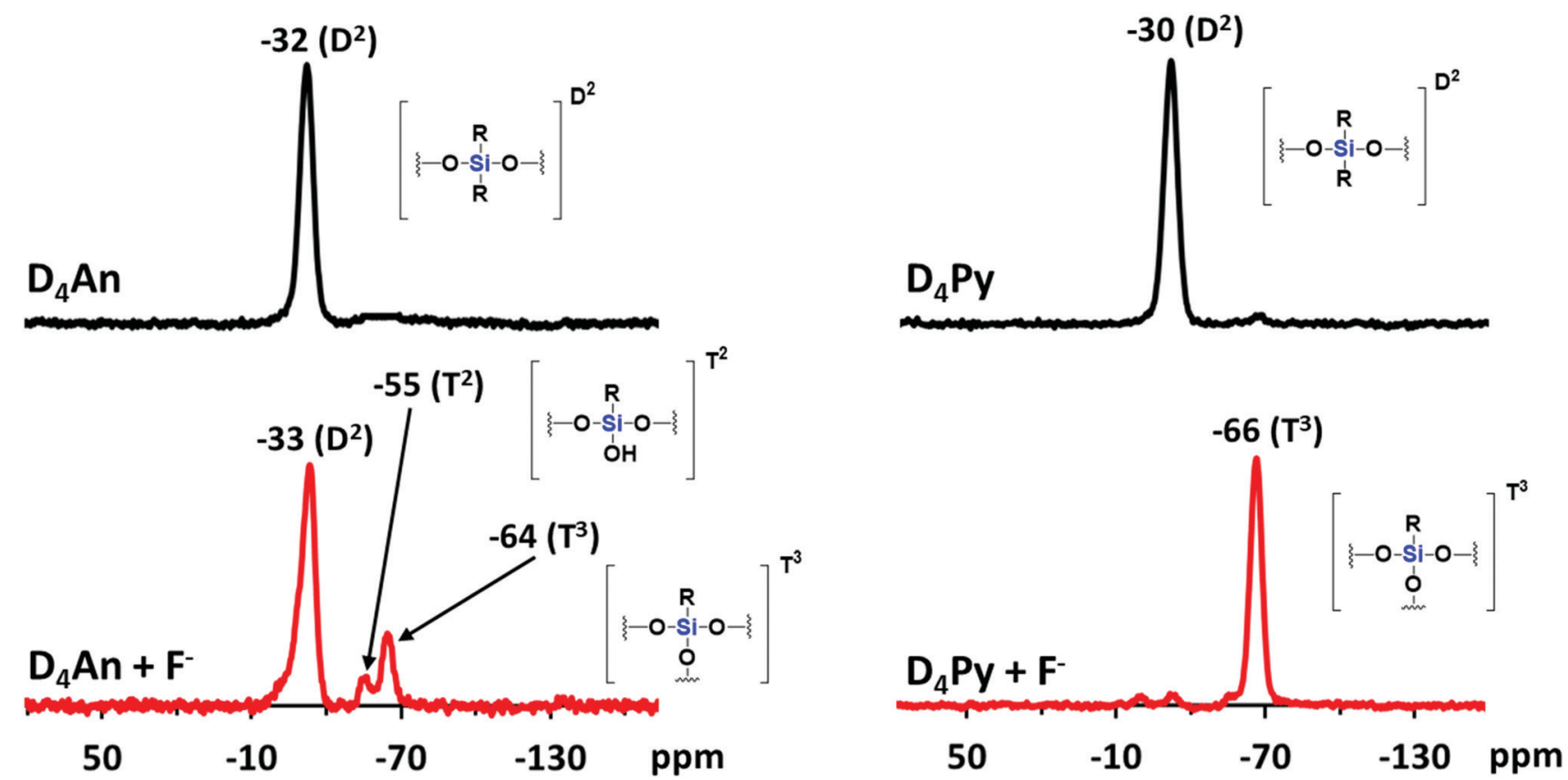

Fig. $5{ }^{29}$ Si MAS NMR spectra of $\mathbf{D}_{\mathbf{4}} \mathbf{A n}$ (left) and $\mathbf{D}_{\mathbf{4}} \mathbf{P y}$ (right) before and after the addition of fluoride (1 equiv.).

that the interaction between fluoride and $\mathbf{D}_{\mathbf{4}} \mathbf{A n}$ or $\mathbf{D}_{\mathbf{4}} \mathbf{P y}$ cleaved the cyclic siloxane.

\section{UV-vis spectroscopy}

In the UV-vis spectra (Fig. S13, ESI $\dagger$ ), the absorption spectrum of $\mathbf{D}_{\mathbf{4}} \mathrm{An}$ showed three major peaks at 360, 379 and $391 \mathrm{~nm}$ while that of $\mathbf{D}_{\mathbf{4}} \mathbf{P y}$ also showed three peaks at 337, 350 and $370 \mathrm{~nm}$. The absorption spectra of $\mathbf{D}_{\mathbf{4}} \mathbf{A n}$ and $\mathbf{D}_{\mathbf{4}} \mathbf{P y}$ in the presence of various anions were studied in an excessive amount (200 equiv.) in THF solvent, as shown in Fig. S14 (ESI $\dagger$ ). The result suggested that $\mathbf{D}_{\mathbf{4}} \mathbf{A n}$ exhibited a new absorption peak at $510 \mathrm{~nm}$ while peaks at 379 and $391 \mathrm{~nm}$ dropped in the presence of $\mathrm{F}^{-}$, and a clear isosbestic point at $415 \mathrm{~nm}$ was observed. The absorption spectra of $\mathbf{D}_{\mathbf{4}} \mathbf{P y}$ at 350 and $368 \mathrm{~nm}$ plummeted whereas a new peak at $493 \mathrm{~nm}$ increased with the isosbestic point at $382 \mathrm{~nm}$ after the addition of $\mathrm{F}^{-}$(Fig. 4b); however, the other anions did not significantly cause a change to the spectral pattern (Fig. S14, ESI $\dagger$ ). The new red-shift band along with the isosbestic point indicated a conversion of the fluorophore to its CT complex with $\mathrm{F}^{-}$. Moreover, the association constant $\left(K_{\mathrm{a}}\right)$ values for the CT complex formation of $\mathbf{D}_{\mathbf{4}} \mathbf{P y}$ and $\mathbf{D}_{\mathbf{4}} \mathbf{A n}$ were $1.2 \times 10^{3}$ and $394 \mathrm{M}^{-1}$, respectively. The detection limits of $\mathrm{F}^{-}$ obtained via UV-vis absorption titration for $\mathbf{D}_{\mathbf{4}} \mathbf{A n}$ and $\mathbf{D}_{\mathbf{4}} \mathbf{P y}$ were $3.6 \times 10^{-5}$ and $1.6 \times 10^{-5} \mathrm{M}$, respectively. The association constant $\left(K_{\mathrm{a}}\right)$, LOD and LOQ of $\mathbf{D}_{\mathbf{4}} \mathbf{A n}$ and $\mathbf{D}_{\mathbf{4}} \mathbf{P y}$ with fluoride in THF are summarized in Table $\mathrm{S} 2$ (ESI $\dagger$ ). These results indicated that $\mathbf{D}_{\mathbf{4}} \mathbf{P y}$ is more sensitive for $\mathrm{F}^{-}$detection in comparison with $\mathbf{D}_{\mathbf{4}} \mathbf{A n}$, which is consistent with the fluorescence titration data described earlier.

\section{Computational study}

Quantum calculations were performed to investigate the changes in fluorescence emission upon the formation of the $\mathbf{D}_{\mathbf{4}} \mathbf{A n}-\mathrm{F}^{-}$ model, which has been speculated as an intermediate before the cleavage of the $\mathrm{D}_{4}$ ring. $\mathrm{D}_{4}$ isomerism basically has four major isomers, which are all-cis, all-trans, cis-trans-cis and cis-cis-trans (Fig. S21, ESI $\dagger$ ). ${ }^{46}$ After geometrical optimization, all-cis and alltrans isomers were the most stable species due to their lower energy compared to the rest (Table S3, ESI $\dagger$ ); therefore, all-cis and all-trans isomers of $\mathbf{D}_{\mathbf{4}} \mathbf{A n}$ were chosen for further study. The photon absorption and fluorescence of all-cis and all-trans $\mathbf{D}_{\mathbf{4}} \mathbf{A n}$ are shown in Fig. 6, and the obtained results were in agreement with our previous report. ${ }^{31}$ A blue shift of fluorescence wavelength was found in both structures evidently from the different conformations of fluorophores caused by $\mathrm{F}^{-} \cdot{ }^{47}$ The pristine formation of anthracene was dominated by graphite-like stacking. When $\mathrm{D}_{4}$ interacted with fluoride, the formation of stacking anthracene changed to slipped-parallel and single monomers in the all-cis and all-trans isomers of $\mathbf{D}_{\mathbf{4}} \mathbf{A n}$, respectively. Therefore, the quantum calculations can well explain the fluorescence wavelength changes after fluoride addition.

\section{Conclusions}

Cyclic siloxane-based anthracene $\left(\mathbf{D}_{\mathbf{4}} \mathbf{A n}\right)$ and pyrene $\left(\mathbf{D}_{\mathbf{4}} \mathbf{P y}\right)$ were successfully synthesized via Heck coupling reaction and showed solvent-dependent fluorescence with a largest Stokes shift $(\Delta \lambda=146 \mathrm{~nm})$. These functionalized cyclic siloxanes in organic solvents exhibited strong fluorescence of intramolecular excimers, which showed excellent selectivity towards $\mathrm{F}^{-}$over other anions. In the presence of fluoride ions, their fluorescence emissions at longer wavelengths, mainly from the radiative relaxation of exciplex species of fluorophores, decreased, while those at shorter wavelengths, caused by the emission of separated fluorophores, increased. The synthesized molecules provided low detection limits in the ranges of $0.2-1.7$ and $0.3-1.0 \mu \mathrm{M}$ for $\mathbf{D}_{\mathbf{4}} \mathbf{A n}$ and $\mathbf{D}_{\mathbf{4}} \mathbf{P y}$, 
a)

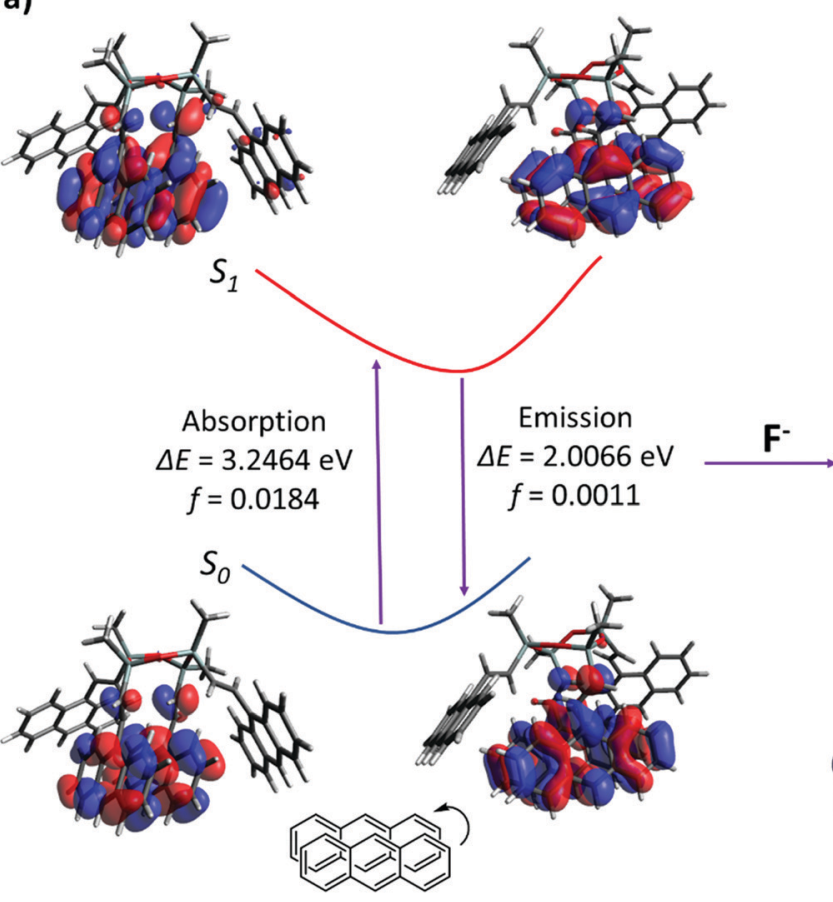

All-cis isomer
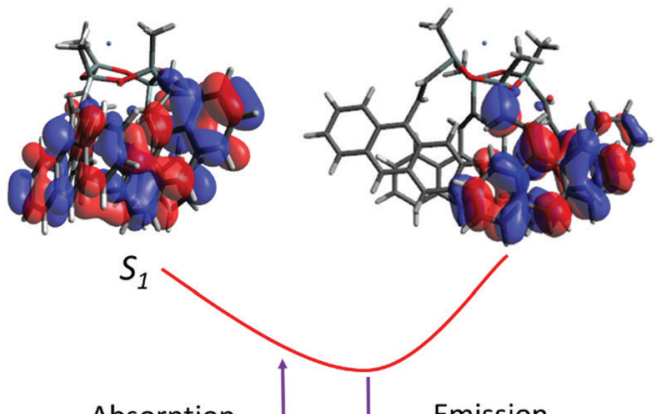

Absorption $\Delta E=3.2767 \mathrm{eV}$ $f=0.1302$ $\Delta E=2.6374 \mathrm{eV}$ $f=0.1176$

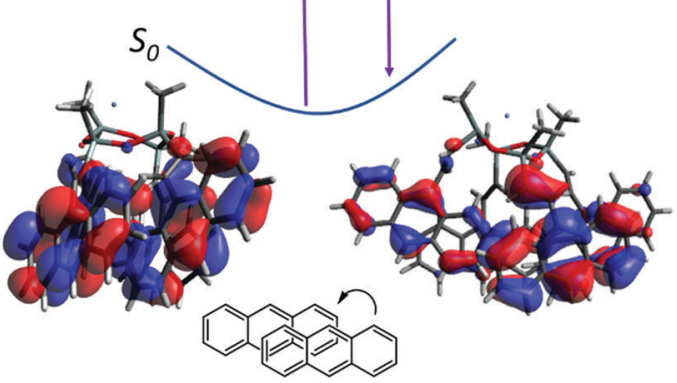

All-cis isomer $+\mathrm{F}$ -

b)
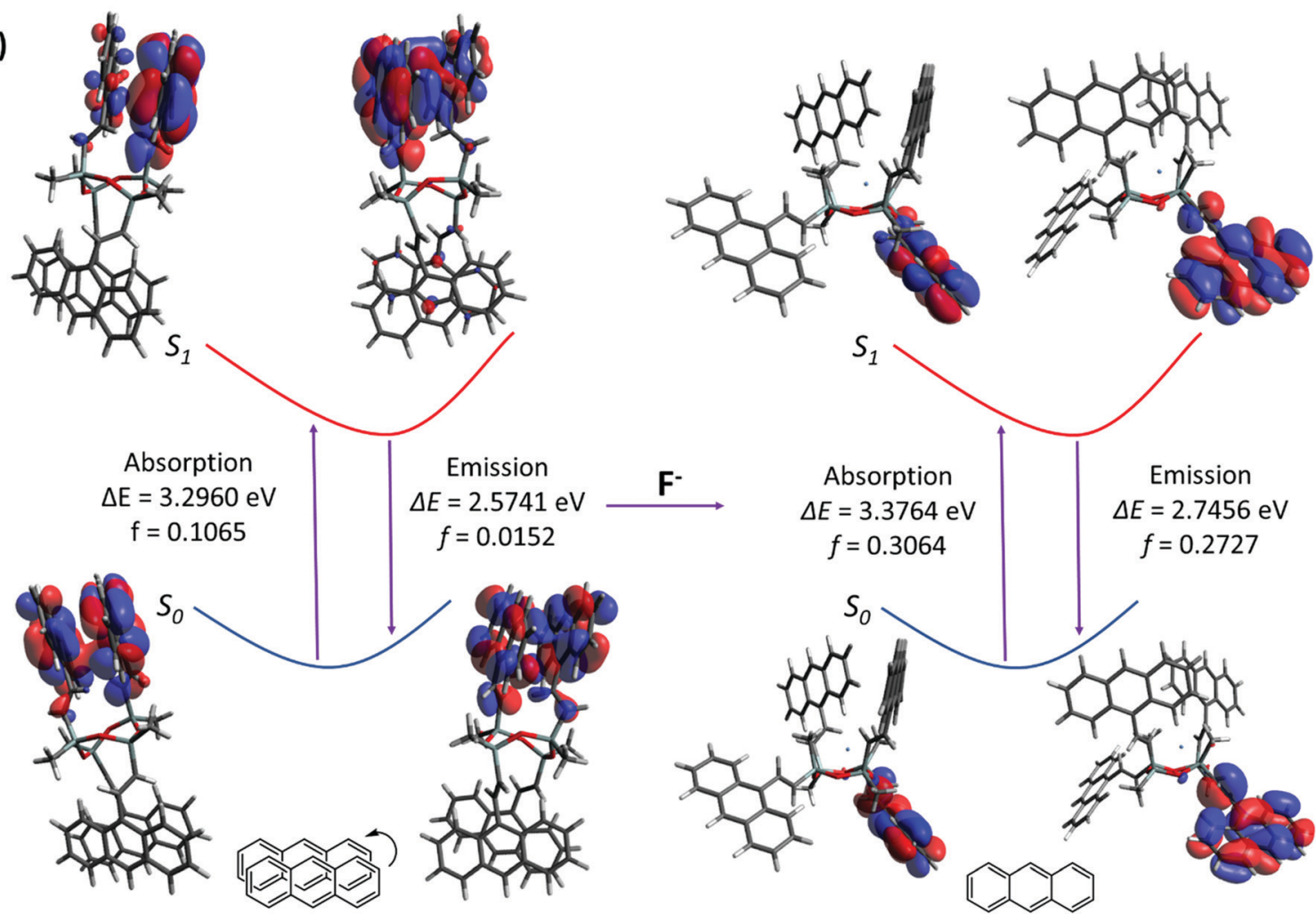

$f=0.3064$

$f=0.2727$

All-trans isomer

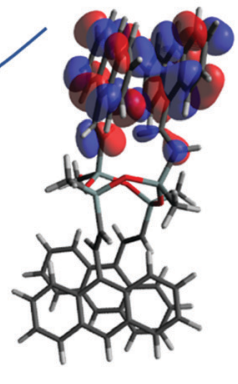

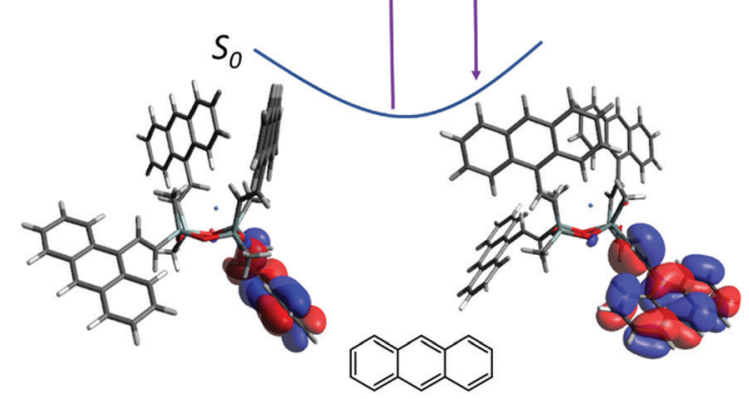

All-trans isomer + F-

Fig. 6 Photoexcitation and emission including oscillator strength ( $f$ ) in Frank-Condo state of (a) all-cis $\mathbf{D}_{\mathbf{4}} \mathbf{A n}$ and (b) all-trans $\mathbf{D}_{\mathbf{4}} \mathbf{A n}$ in vacuo

respectively. Moreover, the naked eye detection of fluoride ions was achieved in THF solvent as the colour changed to pink in $\mathbf{D}_{\mathbf{4}} \mathbf{A n}$ and to orange in $\mathbf{D}_{\mathbf{4}} \mathbf{P y}$. Interestingly, it was found that not only the $\mathrm{Si}-\mathrm{O}$ linkages of cyclic siloxanes were cleaved using $\mathrm{F}^{-}$, but some $\mathrm{Si}-\mathrm{C}$ 
bonds could also be broken and rearranged to form the silsesquioxane ( $\mathrm{T}$ unit) network of silicon. The host-guest interaction was also studied through computational modelling; intramolecular excimer formation within cyclic siloxanes can be interrupted by fluoride ions leading to monomer formation causing a blue-shift of fluorescence emissions. Therefore, cyclic siloxanes can be one of the promising material candidates for $\mathrm{F}^{-}$sensors in organic solvents.

\section{Experiments}

\section{Materials and methods}

2,4,6,8-Tetramethyl-2,4,6,8-tetravinylcyclotetrasiloxane, 1-bromopyrene, 9-bromoanthracene, palladium(II) acetate, triphenylphosphine and triethylamine were purchased from TCI Chemicals. Anhydrous dimethylformamide was purchased from Sigma-Aldrich. Commercial solvents such as dichloromethane were further distilled. UV-vis spectra were recorded on a UV-vis spectrometer (Shimadzu UV-2600). All fluorescence emission spectra were recorded using a spectrometer (Horiba FluoroMax4+, slit width: $2 \mathrm{~nm}$ ). The FTIR spectra were recorded using the attenuated total reflectance (ATR) technique on a Bruker Alpha spectrometer. High resolution ESI-MS spectra (positive mode) were measured on a micrOTOF instrument. MALDI-TOF MS was performed on a Bruker Autoflex instrument with trans-2-[3-(4-tert-Butylphenyl)-2methyl-2-propenylidene]malononitrile as a matrix.

\section{Synthetic procedures}

Synthesis of 2,4,6,8-tetrakis((E)-2-(anthracen-9-yl)vinyl)-2,4,6,8tetramethyl-1,3,5,7,2,4,6,8-tetraoxatetrasilocane $\left(D_{4} A n\right)$. First, 9-bromoanthracene (1.54 g; $6 \mathrm{mmol}$ ) and triphenylphosphine (0.1311 g; $0.5 \mathrm{mmol}$ ) were added into a $200 \mathrm{~mL}$ heavy wall pressure vessel tube. Then, anhydrous dimethylformamide $(15 \mathrm{~mL})$, triethylamine $(3.5 \mathrm{~mL})$ and 2,4,6,8-tetramethyl-2,4,6,8-tetravinylcyclotetrasiloxane $(0.35 \mathrm{~mL} ; 1 \mathrm{mmol})$ were added into the tube, respectively. The reaction mixture was exposed to a flow of argon gas for 5 minutes, and then palladium(II) acetate (0.0229 $\mathrm{g} ; 0.1 \mathrm{mmol})$ was added into the solution. The reaction mixture was stirred at $100{ }^{\circ} \mathrm{C}$ for 3 days. After cooling to room temperature, the solution was filtered for removing the palladium catalyst using Celite. The filtrate was precipitated with ice and a dark crude product was obtained, which was filtered and subsequently washed with deionized water. Then, the crude product was eluted via flash column chromatography using dichloromethane as an eluent. A dark orange powder was obtained, which was further purified via Soxhlet extraction using methanol and hexane (one day per extraction). A dark orange product was obtained $\left(0.7634 \mathrm{~g}, 73 \%\right.$ yield). Solid state ${ }^{1} \mathrm{H}$ MAS NMR (400 MHz, $\delta$ ): 0.02-1.29 ppm $\left(-\mathrm{CH}_{3}\right)$ and $6.28 \mathrm{ppm}(\mathrm{Ar}-\mathrm{H})$, as shown in Fig. S2 (ESI $\dagger$ ). Solid state ${ }^{29} \mathrm{Si} \mathrm{MAS} \mathrm{NMR} \mathrm{(400} \mathrm{MHz,} \delta$ ): $-32 \mathrm{ppm}$, as depicted in Fig. 5. MALDI-TOF MS for 4 anthracene subunits $(n=4)$, calcd $\mathrm{C}_{68} \mathrm{H}_{56} \mathrm{O}_{4} \mathrm{Si}_{4}+\mathrm{H}^{+}: m / z 1049.333\left[\mathrm{M}+\mathrm{H}^{+}\right]$; found: $m / z 1049.429$ (Fig. S3, ESI $\dagger$ ). The FTIR spectrum showed a vibration band in the range of $2873-3048 \mathrm{~cm}^{-1}$ (-CH stretching) and at $1049 \mathrm{~cm}^{-1}$ (Si-O-Si stretching), as shown in Fig. S8 (ESI $\dagger$ ).
Synthesis of 2,4,6,8-tetramethyl-2,4,6,8-tetrakis $((E)$-2-(pyren1-yl)vinyl)-1,3,5,7,2,4,6,8-tetraoxatetrasilocane ( $\left.\mathrm{D}_{4} \mathrm{Py}\right)$. 1-Bromopyrene (1.69 g; $6 \mathrm{mmol})$ and triphenylphosphine $(0.1311 \mathrm{~g} ; 0.5 \mathrm{mmol})$ were added into a $200 \mathrm{~mL}$ heavy wall pressure vessel tube. Then, $15 \mathrm{~mL}$ of anhydrous dimethylformamide, $3.5 \mathrm{~mL}$ of triethylamine and 2,4,6,8tetramethyl-2,4,6,8-tetravinylcyclotetrasiloxane $(0.35 \mathrm{~mL} ; 1 \mathrm{mmol})$ were added into the vessel tube. Argon flow was introduced into the solution for 5 minutes, and then palladium(II) acetate $(0.0229 \mathrm{~g}$; $0.1 \mathrm{mmol}$ ) was added into the solution. The reaction mixture was stirred and heated at $100{ }^{\circ} \mathrm{C}$ for 3 days. Then, the solution was cooled to room temperature and filtered using a Buchner funnel to remove the insoluble catalyst. The solution was precipitated with crushed ice cubes. The crude product was filtered and washed with deionized water. The residue was eluted via flash column chromatography on silica gel using dichloromethane as an eluent and then further purified by using Soxhlet extraction in methanol and hexane (one day per extraction). A yellow powder was obtained (0.9968 g, $87 \%$ yield). Solid state ${ }^{1} \mathrm{H}$ MAS NMR (400 MHz, $\delta$ ): 0.03 ppm $\left(-\mathrm{CH}_{3}\right)$ and 5.97 ppm (Ar-H), as shown in Fig. S2 (ESI $\dagger)$. Solid state ${ }^{29} \mathrm{Si}$ MAS NMR (400 MHz, $\delta$ ): -30 ppm, as depicted in Fig. 5. MALDI-TOF MS for 4 substitutions of pyrene $(n=4)$, calcd $\mathrm{C}_{76} \mathrm{H}_{56} \mathrm{O}_{4} \mathrm{Si}_{4}+\mathrm{H}^{+}: m / z$ 1145.333 [M $\left.+\mathrm{H}^{+}\right]$; found: $m / z 1145.778$ (Fig. S3, ESI $\dagger$ ). The FTIR spectrum showed a vibration peak in the range of $2872-3082 \mathrm{~cm}^{-1}$ (-CH stretching) and at $1039 \mathrm{~cm}^{-1}$ (Si-O-Si stretching), as shown in Fig. S8 (ESI $\dagger)$.

\section{Fluorescence and absorption studies of $\mathrm{D}_{4} \mathrm{An}$ and $\mathrm{D}_{4} \mathrm{Py}$ with anions}

The stock solutions of anions $\left(\right.$ e.g. $\mathrm{F}^{-}, \mathrm{Cl}^{-}, \mathrm{Br}^{-}, \mathrm{CN}^{-}, \mathrm{ClO}_{4}^{-}$, $\mathrm{NO}_{3}{ }^{-}$and $\mathrm{PO}_{4}{ }^{3-}$ ) in the form of tetrabutylammonium salts in THF were each prepared at $0.1 \mathrm{M}$. Then, solutions of $\mathbf{D}_{\mathbf{4}} \mathbf{A n}(2 \times$ $\left.10^{-5} \mathbf{M}\right)$ and $\mathbf{D}_{4} \mathbf{P y}\left(1 \times 10^{-5} \mathbf{M}\right)$ in all solvents (e.g. toluene, THF, DMF and DMSO) were prepared. The fluorescence spectra were measured with the addition of anions at 1 and 200 equiv. into the solution of $\mathbf{D}_{\mathbf{4}} \mathbf{A n}$ or $\mathbf{D}_{\mathbf{4}} \mathbf{P y}(2 \mathrm{~mL})$. On the other side, $\mathbf{D}_{\mathbf{4}} \mathbf{A n}$ $\left(4 \times 10^{-5} \mathrm{M}\right)$ and $\mathbf{D}_{4} \mathbf{P y}\left(2 \times 10^{-5} \mathrm{M}\right)$ in THF were used for the absorption study. The UV-vis adsorption spectra were recorded in the solution of $\mathbf{D}_{\mathbf{4}} \mathbf{A n}$ or $\mathbf{D}_{\mathbf{4}} \mathbf{P y}(2 \mathrm{~mL})$ after the addition of anions (200 equiv.). All UV-vis and fluorescence spectra were recorded at room temperature.

\section{Fluorescence and absorption titration of $\mathrm{D}_{4} \mathrm{An}$ and $\mathrm{D}_{4} \mathrm{Py}$ with fluoride}

All tests were carried out at room temperature. The concentrations of $\mathbf{D}_{\mathbf{4}} \mathbf{A n}\left(2 \times 10^{-5} \mathbf{M}\right)$ and $\mathbf{D}_{\mathbf{4}} \mathbf{P y}\left(1 \times 10^{-5} \mathbf{M}\right)$ in all solvents were used for the fluorescence experiment. The solutions of $\mathbf{D}_{\mathbf{4}} \mathbf{A n}$ and $\mathbf{D}_{\mathbf{4}} \mathbf{P y}(2 \mathrm{~mL})$ were added into a quartz cuvette. Then, $5-140 \mu \mathrm{L}$ of the fluoride solution $\left(10^{-3} \mathrm{M}\right)$ was added into the cuvette. After stirring the solution for 3 minutes, the fluorescence spectra were recorded. For the absorption experiment, $\mathbf{D}_{\mathbf{4}} \mathbf{A n}\left(4 \times 10^{-5} \mathrm{M}\right)$ and $\mathbf{D}_{\mathbf{4}} \mathbf{P y}\left(2 \times 10^{-5} \mathrm{M}\right)$ in THF $(2 \mathrm{~mL})$ were placed in the cuvette, followed by the addition of the fluoride solution (0.06 $\mathrm{M}$ and $0.03 \mathrm{M}$ ) in the range of 5-60 $\mu \mathrm{L}$ into $\mathbf{D}_{\mathbf{4}} \mathbf{A n}$ and $\mathbf{D}_{\mathbf{4}} \mathbf{P y}$ solutions, respectively. The absorption spectra were recorded after stirring the solution for 3 minutes. 


\section{Computational study}

The quantum calculations were performed using Gaussian 16 using density functional theory (DFT) and time-dependent density functional theory (TD-DFT); the M062X functional and Def2SVP basis set were used for all calculations in vacuo. ${ }^{48}$ The positive frequency of each geometry in its ground state was checked to validate the optimized structure. The molecular orbitals were visualized using the Avogadro software. ${ }^{49}$

\section{Conflicts of interest}

There are no conflicts to declare.

\section{Acknowledgements}

This research project was supported by the Thailand Research Fund (RSA6280049 and RTA6180007), the Center of Excellence for Innovation in Chemistry (PERCH-CIC), the Ministry of Higher Education, Science, Research and Innovation (MHESI), and the Faculty of Science, Mahidol University through a CIF grant.

\section{Notes and references}

1 Y. Horii and K. Kannan, Arch. Environ. Contam. Toxicol., 2008, 55, 701.

2 C. Racles, M. Silion and L. Sacarescu, Colloids Surf., A, 2018, 547, 102-110.

3 Z. Han, A. Fina and G. Camino, in Polymer Green Flame Retardants, ed. C. D. Papaspyrides and P. Kiliaris, Elsevier, Amsterdam, 2014, pp. 389-418, DOI: 10.1016/B978-0-44453808-6.00012-3.

4 H. Brothers, T. Boehmer, R. Campbell, S. Dorn, J. Kerbleski, S. Lewis, C. Mund, D. Pero, K. Saito, M. Wieser and W. Zoller, Int. J. Cosmet. Sci., 2017, 39, 580-588.

5 E. Yilgör and I. Yilgör, Prog. Polym. Sci., 2014, 39, 1165-1195.

6 T. M. Tran, H. T. Le, N. D. Vu, G. H. Minh Dang, T. B. Minh and K. Kannan, Chemosphere, 2017, 184, 1117-1124.

7 T. B. Longenberger, K. M. Ryan, W. Y. Bender, A.-K. Krumpfer and J. W. Krumpfer, J. Chem. Educ., 2017, 94, 1682-1690.

8 Y. Song, M. Liu, L. Zhang, C. Mu and X. Hu, Chem. Eng. J., 2017, 328, 274-279.

9 T. Zhao, R. Yu, S. Li, X. Li, Y. Zhang, X. Yang, X. Zhao, C. Wang, Z. Liu, R. Dou and W. Huang, ACS Appl. Mater. Interfaces, 2019, 11, 14391-14398.

$10 \mathrm{H}$. Fromme, in Encyclopedia of Environmental Health, ed. J. Nriagu, Elsevier, Oxford, 2nd edn, 2019, pp. 805-812, DOI: 10.1016/B978-0-12-409548-9.11241-2.

11 N. Espinosa, J. López, F. Flores Gracia, A. D. de la Luz and J. Martínez-Juárez, Adv. Mater. Lett., 2016, 7, 480-484.

12 C. Racles, M. Cazacu, B. Fischer and D. Opris, Smart Mater. Struct., 2013, 22, 104004.

13 Y. Meng, J. Chu, J. Xue, C. Liu, Z. Wang and L. Zhang, RSC Adv., 2014, 4, 31249-31260.
14 X. Zhan, X. Cai and J. Zhang, RSC Adv., 2018, 8, 12517-12525.

15 Y. Looi, M. Riduwan, M. B. H. Othman, R. Ramli, Z. Ishak and Z. Ahmad, Polym. Int., 2013, 62, 382-389.

16 L. Y. Tyng, M. R. Ramli, M. B. H. Othman, R. Ramli, Z. A. M. Ishak and Z. Ahmad, Polym. Int., 2013, 62, 382-389.

17 Q. Li, Z. Yang, Z. Ren and S. Yan, Macromol. Rapid Commun., 2016, 37, 1772-1779.

18 Y. Liang, L. Xu, F. Qu, K. Tang, H. Wang and W. W. Yu, Polym. Chem., 2019, 10, 4818-4824.

19 T. Zheng, Z. Xu, Y. Zhao, H. Li, R. Jian and C. Lu, Sens. Actuators, B, 2018, 255, 3305-3315.

20 Z. Gou, X. Zhang, Y. Zuo, M. Tian, B. Dong and W. Lin, ACS Appl. Mater. Interfaces, 2019, 11, 30218-30227.

21 Y. Li, J. Chen and T.-S. Chu, J. Comput. Chem., 2018, 39, 1639-1647.

22 N. Borah, B. Nayak, A. Gogoi and G. Das, New J. Chem., 2019, 43, 16497-16505.

23 W. Ding, J. Xu, Y. Wen, J. Zhang, H. Liu and Z. Zhang, Anal. Chim. Acta, 2017, 967, 78-84.

24 D. Liu, L. Shi, S.-H. Gao, Y.-H. Wu, G.-Y. Li and C.-H. Zhou, Chem. Phys. Lett., 2020, 738, 136894.

25 Z. Li, S. Wang, L. Xiao, X. Li, X. Shao, X. Jing, X. Peng and L. Ren, Inorg. Chim. Acta, 2018, 476, 7-11.

26 L. Wang, W. Li, J. Lu, J.-P. Zhang and H. Wang, Tetrahedron, 2014, 70, 3172-3177.

27 P. Hou, S. Chen, H. Wang, J. Wang, K. Voitchovsky and X. Song, Chem. Commun., 2014, 50, 320-322.

28 B. Qiu, Y. Zeng, L. Cao, R. Hu, X. Zhang, T. Yu, J. Chen, G. Yang and Y. Li, RSC Adv., 2016, 6, 49158-49163.

29 N. Prigyai, S. Chanmungkalakul, V. Ervithayasuporn, N. Yodsin, S. Jungsuttiwong, N. Takeda, M. Unno, J. Boonmak and S. Kiatkamjornwong, Inorg. Chem., 2019, 58, 15110-15117.

30 S. Chanmungkalakul, V. Ervithayasuporn, S. Hanprasit, M. Masik, N. Prigyai and S. Kiatkamjornwong, Chem. Commun., 2017, 53, 12108-12111.

31 S. Chanmungkalakul, V. Ervithayasuporn, P. Boonkitti, A. Phuekphong, N. Prigyai, S. Kladsomboon and S. Kiatkamjornwong, Chem. Sci., 2018, 9, 7753-7765.

32 C. Wannasiri, S. Chanmungkalakul, T. Bunchuay, L. Chuenchom, K. Uraisin, V. Ervithayasuporn and S. Kiatkamjornwong, ACS Appl. Polym. Mater., 2020, 2, 1244-1255.

33 S. E. Anderson, D. J. Bodzin, T. S. Haddad, J. A. Boatz, J. M. Mabry, C. Mitchell and M. T. Bowers, Chem. Mater., 2008, 20, 4299-4309.

34 P. K. Lekha and E. Prasad, Chem. - Eur. J., 2010, 16, 3699-3706. 35 H. Liu, X. Yan, L. Shen, Z. Tang, S. Liu and X. Li, Mater. Horiz., 2019, 6, 990-995.

36 E. V. Bichenkova, A. R. Sardarian, A. N. Wilton, P. Bonnet, R. A. Bryce and K. T. Douglas, Org. Biomol. Chem., 2006, 4, 367-378.

37 M. Kanai, T. Hirano, I. Azumaya, I. Okamoto, H. Kagechika and A. Tanatani, Tetrahedron, 2012, 68, 2778-2783.

38 Z. Guo, S. Jin and B. Liu, Spectrochim. Acta, Part A, 2007, 66, 672-675. 
39 M. M. Islam, Z. Hu, Q. Wang, C. Redshaw and X. Feng, Mater. Chem. Front., 2019, 3, 762-781.

40 J. Kim, L. J. Cote, F. Kim and J. Huang, J. Am. Chem. Soc., 2010, 132, 260-267.

41 M. Danko, P. Kasák and P. Hrdlovič, J. Photochem. Photobiol., A, 2015, 307-308, 79-87.

42 Å. Östlund, D. Lundberg, L. Nordstierna, K. Holmberg and M. Nydén, Biomacromolecules, 2009, 10, 2401-2407.

43 K. O. Christe and W. W. Wilson, J. Fluorine Chem., 1990, 46, 339-342.

44 R. M. Laine and M. Z. Asuncion, US20140120243A1, 2014.

45 M. Ge and H. Liu, Chem. - Eur. J., 2018, 24, 2224-2231.

46 I. Ryuichi, K. Yuriko and K. Yusuke, Chem. Lett., 2009, 38, 364-365.

47 C. Zhao, X. Cai, Z. Ma, J. Shi, L. Xu and H. Wang, J. Photochem. Photobiol., A, 2018, 355, 318-325.

48 M. J. Frisch, G. W. Trucks, H. B. Schlegel, G. E. Scuseria, M. A. Robb, J. R. Cheeseman, G. Scalmani, V. Barone,
G. A. Petersson, H. Nakatsuji, X. Li, M. Caricato, A. V. Marenich, J. Bloino, B. G. Janesko, R. Gomperts, B. Mennucci, H. P. Hratchian, J. V. Ortiz, A. F. Izmaylov, J. L. Sonnenberg, Williams, F. Ding, F. Lipparini, F. Egidi, J. Goings, B. Peng, A. Petrone, T. Henderson, D. Ranasinghe, V. G. Zakrzewski, J. Gao, N. Rega, G. Zheng, W. Liang, M. Hada, M. Ehara, K. Toyota, R. Fukuda, J. Hasegawa, M. Ishida, T. Nakajima, Y. Honda, O. Kitao, H. Nakai, T. Vreven, K. Throssell, J. A. Montgomery Jr., J. E. Peralta, F. Ogliaro, M. J. Bearpark, J. J. Heyd, E. N. Brothers, K. N. Kudin, V. N. Staroverov, T. A. Keith, R. Kobayashi, J. Normand, K. Raghavachari, A. P. Rendell, J. C. Burant, S. S. Iyengar, J. Tomasi, M. Cossi, J. M. Millam, M. Klene, C. Adamo, R. Cammi, J. W. Ochterski, R. L. Martin, K. Morokuma, O. Farkas, J. B. Foresman and D. J. Fox, Gaussian, Inc., Wallingford CT, 2016.

49 M. D. Hanwell, D. E. Curtis, D. C. Lonie, T. Vandermeersch, E. Zurek and G. R. Hutchison, J. Cheminf., 2012, 4, 17. 